\title{
A RARE CASE OF GIANT GALL STONE IN A YOUNG PREPUBERTAL FEMALE
} Nisha Kaul ${ }^{1}$, Vinod Kaul ${ }^{2}$

\section{HOW TO CITE THIS ARTICLE:}

Nisha Kaul, Vinod Kaul. "A Rare Case of Giant Gall Stone in a Young Prepubertal Female". Journal of Evolution of Medical and Dental Sciences 2015; Vol.4, Issue 44, June 01; Page: 7695-7698, D0I: 10.14260/jemds/2015/1119

ABSTRACT: The incidence of gallbladder stone disease (Cholelithiasis) is rising high in our country due to changes in life style and food habits. Its prevalence is more in females as compared to males. Besides various well established causes of cholelithiasis, some important anatomical/genetic factors playing a pivotal role in the stone formation are: 1. Crypts or sinuses in the mucosal folds of gallbladder called crypts of luschka. 2. LiTh1 and LiTh2 genes concerned with cholesterol metabolism, and polymorphism of apo-lipoprotein B gene. These above mentioned factors need to be considered as important etiopathogenic basis in the gallstone formation especially in high risk patients. An extra mural compression of CBD by a giant gall stone with clinical features simulating as choledocolithiasis (An example of exception of Courvoisier's law) should also be kept in mind while planning the line of treatment.

KEYWORDS: Cholelithiasis, crypts of luschka, genes- LiTh1, LiTh2.

INTRODUCTION: The gall stone disease (Cholelithiasis) is a very common entity, being more prevalent in females. Its prevalence is more common in western world than in Asia. Its presentation is very rare in first two decades, particularly in children.(1,2)

The stones vary in size from tiny sand granules or small pebbles to a small single stone or a large single stone of the size of a golf ball.(2) The incidence of any large sized stone more than $5 \mathrm{cms}$ is known to be very rare.(3) The Gallstones are coagulated bile formed due to super saturation of any of its solute contents. ${ }^{(4)}$ The bile consists of $92 \%$ of water and $8 \%$ of solutes which include cholesterol, bile salts and bilirubin predominantly.(5) Any one of the solutes exceeding its maximum solubility precipitates and leads to stone formation.(6) The gall stones are classified as cholesterol, pigment and mixed stones.(4) Various predisposing factors responsible for gallstone formation are: intake of rich fatty diet, females, obesity, elderly population, diabetes mellitus type 1, intake of oral contraceptives, alcoholic cirrhosis, rapid weight loss, spinal cord injury, haemolytic anaemias etc.(1) Certain anatomical/genetic factors playing a vital role in stone formation include:

a) Crypts of luschka in the mucosal folds of gall bladder, (7) which reduce the smoothness of mucosa lining, making it uneven, thereby forming a potential nidus for deposition of bile solutes, when they exceed their solubility.

b) Atonic gallbladder following vagotomy, autonomic neuropathy, lithogenic bile, spinal cord injury etc.(1) It causes bile stasis leading to precipitation of solutes as bile sludge.

c) Lithogenic genes -LiTh1 andLiTh2 genes favour cholesterol stone formation.(8) Polymorphism of Apo-lipo protein B (APO B) gene is associated with altered serum lipids, susceptibility to gall stone formation and malignancy of gall bladder.(9) Simple gallstones may remain asymptomatic for years or present conventionally as:

a. Acute cholecystitis with colicky pain in right hypochondric region.

b. Tenderness in the same area.

c. Features of systemic toxicity e.g., fever, leucocytosis without manifestation of icterous. Jaundice occurs when stone slips \& obstructs common bile duct.(4) 
A CASE REPORT: An eleven years old pre pubertal girl, was brought to the surgical emergency of a private hospital, New Delhi with h/o pain in right upper abdomen and vomiting for one day. On general examination, the patient was febrile with tachycardia, dehydration \& mild icterous. BP was within normal limits. On abdominal examination: A smooth lump was palpated in right hypochondrium about two fingers below right costal margin. The mass was moving with respiration. Murphy's sign was positive.

Ultra sound abdomen revealed a big hypo echogenic shadow in the region of gall bladder suggesting the presence of cholelithiasis. Gall bladder was enlarged in size measuring $12 \times 3 \mathrm{cms}$.

TREATMENT: The patient was resuscitated and prepared for laparoscopic cholecystectomy. On the operation table, the laparoscope revealed a large distended gall bladder, having adhesions with adjacent structures. A big stone was felt within it. Laparoscopic cholecystectomy was attempted but the procedure failed due to multiple adhesions and inability to remove giant stone through lap hole. Hence open cholecystectomy was undertaken. The gall bladder was resected out and incised. A giant stone measuring $8 \times 3 \mathrm{cms}$ was taken out. [Fig 1a; 1b] Besides it, multiple small pebble like stones occupying the fundus of gall bladder were also taken out. [Fig-2]

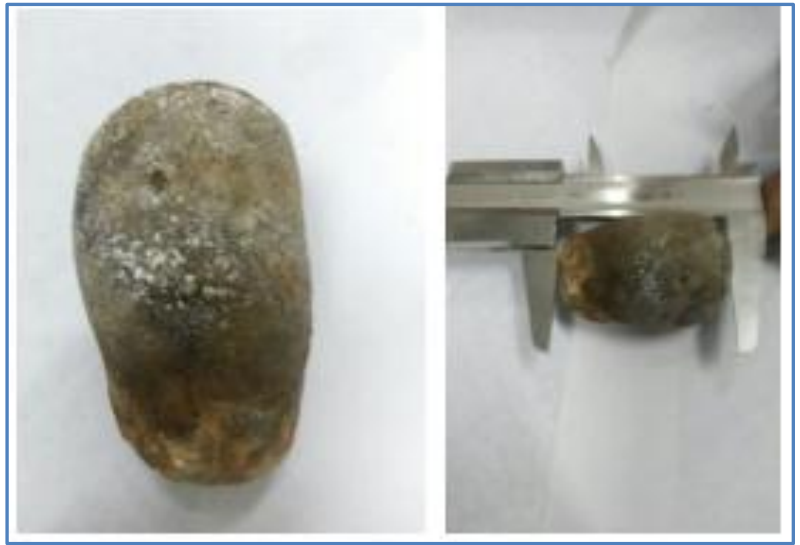

Fig. 1a \& 1b: Showing the giant gall stone

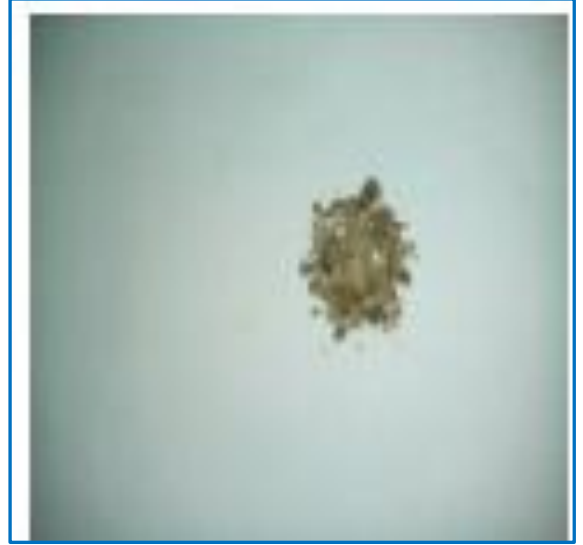

Fig. 2: Showing multiple Pebble like stones

DISCUSSION: The occurrence of giant gall stone though rare has been reported by many authors. Almost all patients reported, were elderly males or females but in our case the patient was a young thin built girl of just 11 years age having a large stone measuring $8 \times 3 \mathrm{cms}$.

In some cases the giant gall stone presented as conventional gall bladder disease but in others it was diagnosed only as rare complications of cholelithiasis.

A giant molded gall bladder stone following choledochal ascariasis was reported by de Juan MARTIN $\mathrm{M}$ et al.(10) A huge gall stone measuring $17 \times 10 \mathrm{cms}$ was detected in a 57 years old diabetic man by PABLO B et al.(11) The gall stones associated with adenocarcinoma and empyema of gall bladder in an 87 years old man was reported by HSU KF et al.(12) Some unusual rare presentations of big gallstones have also been reported as:

a. Mirizzi's syndrome where extra mural compression of CBD by a large stone mimicked the features of choledocolithiasis rather than plain cholelithiasis. $(4,13)$ 
b. Bouveret's syndrome - as acute gastric outlet obstruction. Here a cholecysto- duodenal fistula following pressure necrosis of gall bladder and adjacent duodenal wall by a giant gall stone was formed; the stone slipped through fistula into the first part of duodenum and obstructed the gastric outlet. Terminal ileal obstruction caused by gall stone slipping down up to ileocaecal junction leading to small bowel obstruction has also been reported.(4)

c. External biliary fistula of gallbladder with anterior abdominal wall following prolonged cholelithiasis though very rare, has also been a rare presentation of giant gall stone (14). Long standing gallstones can lead to the complications like chronic cholecystitis, choledocholiithiasis, cholangitis, cholestasis, pancreatitis and carcinoma of gall bladder etc.(15) besides the above mentioned ones as quoted by various authors.

CONCLUSION: Gallstone pathology can also occur at any age even at a very young age of childhood and in thin built patients besides middle aged people.

The conventional predisposing factors indicated over a long period of time need not to be the only causative factors for cholelithiasis. In our study we have also seen a very rare presentation of Mirizzi's syndrome in a young 11 years old pre-pubertal girl with a giant gall stone. This further emphasizes the role of anatomic/genetic basis as one of the first few important predisposing factors in the pathogenesis of cholelithiasis particularly in young children.

\section{REFERENCES:}

1. Pitchumoni c s. Increasing Prevalance of Gall Stone; Diagnostic and Therapeutic Options. Medicine Update. 2010; vol. 20, 7: 5B: 486-500.

2. Dalal s, Pankaj, Bhoriwal s, et al Giant Gall stone: A Rare Indication of open Cholecystectomy. Journal of Case Report. 2014; 4 (1): 17-19.

3. Xiequn $\mathrm{Xu}$, Tao Hong, Chaoji Zheng. Giant Gall Stone performed by emergency laproscopic cholecystectomy. Int J Surg Rep.2013; 49120: 1163-1164.

4. Ahmed A, Cheung R C, Keeffe E B. Management of Gall Stones andtheir Complications. Am Fam Physician. 2000 Mar 15; 61 (6): 1673-1680.

5. Guyton AC, Hall J E. Secretion of bile by the liver; functions of the biliary tree. GUYTON AND HALL TEXT BOOK OF MEDICAL PHYSIOLOGY. 2008; 11 th edition: $p$ 802-804.

6. Donovan J M. Physical and metabolic factors in gallstone pathogenesis. Gastroentrol clin North Am.1999; 28: 75-79.

7. Ross MH, Reith E J. Digestive system lll: Liver, Gallbladder and Pancreas. HISTOLOGY A TEXT AND ATLAS; 1985: P 472-502.

8. Monica ACALOVSCHI. Genetic factors in cholesterol gallstone disease. MAEdicA -a Journal of clinical Medicine. 2006; vol 1 No 1: p 49 -58.

9. Singh MK, Pandey UB, Ghoshal UC, et al Apo-lipoprotein B-100 Xbal gene polymorphism in gallbladder cancer. Hum Genet. Feb 2004; 114 (3): 280-3.

10. De Jaun Martin M, Rodri'guez Villa A, Capdevilla Puerta A. Et al Giant molded gallbladder stone in biliary lithiasis following choledochal ascariasis. Rev Esp Enferm Apar Dig. 1985; 67: 362365.

11. Pablo B, Valentina B, Christian A. Et al Giant gallstone: A case report. Int J Surg Case Rep.2011; 2 (7): 228-229. 


\section{CASE REPORT}

12. Hsu KF, Yeh C L, Shin ML, et al Giant Gall bladder: Adenocarcinoma Complicated with Empyema. The journal of TRAUMA injury infection and critical care. Jan 2011; vol. 70, Number 1: p 261.

13. Ludmil MV, Mannol AK, Todor AT Mirizzi's syndrome-a rare cause of major biliary complication. Journal of IMAB -annual proceedings (scientific paper) 2009 vol. 109, book 1, p92-94.

14. Aly H. El Shehry. Biliary Fistulas. Egyptian Journal of Surgery. Jan 2004; Vol. (23), No (1): p 98113.

15. Williams NS, Christopher JK Bulstrode, O'Connel PR The gall bladder and bile ducts. Bailey \&Love's short practice of surgery.2013; 26 th edition; CRC LONDON: P1107.

\section{AUTHORS:}

1. Nisha Kaul

2. Vinod Kaul

\section{PARTICULARS OF CONTRIBUTORS:}

1. Professor, Department of Anatomy, Santosh Medical College, Ghaziabad, Utter Predesh.

2. Senior Laparoscopic Surgeon, Fortis Aslok Hospital, Sufderjung Enclave, New Bdelhi.

\section{NAME ADDRESS EMAIL ID OF THE}

\section{CORRESPONDING AUTHOR:}

Dr. Nisha Kaul,

\# 23, Double Storey,

New Rajinder Nagar,

New Delhi-110060.

E-mail: nishakaul.nk@gmail.com

Date of Submission: 08/05/2015.

Date of Peer Review: 09/05/2015.

Date of Acceptance: 23/05/2015.

Date of Publishing: 01/06/2015. 